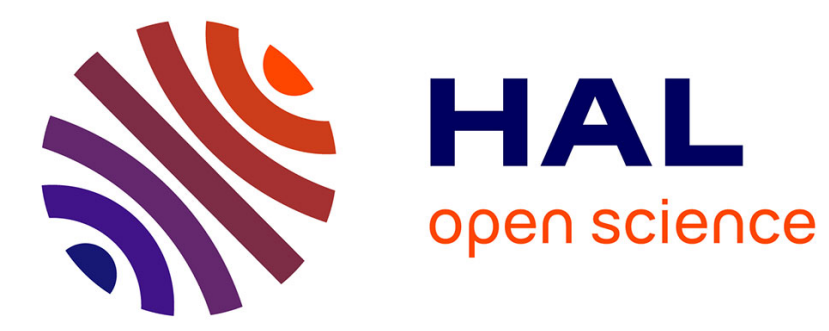

\title{
The jet pulse power supply system
}

\author{
J.B. Hicks
}

\section{To cite this version:}

J.B. Hicks. The jet pulse power supply system. Revue de Physique Appliquée, 1977, 12 (12), pp.18231828. 10.1051/rphysap:0197700120120182300 . jpa-00244409

\section{HAL Id: jpa-00244409 https://hal.science/jpa-00244409}

Submitted on 1 Jan 1977

HAL is a multi-disciplinary open access archive for the deposit and dissemination of scientific research documents, whether they are published or not. The documents may come from teaching and research institutions in France or abroad, or from public or private research centers.
L'archive ouverte pluridisciplinaire HAL, est destinée au dépôt et à la diffusion de documents scientifiques de niveau recherche, publiés ou non, émanant des établissements d'enseignement et de recherche français ou étrangers, des laboratoires publics ou privés. 


\title{
THE JET PULSE POWER SUPPLY SYSTEM
}

\author{
J. B. HICKS \\ JET Design Team, Culham Laboratory, Abingdon, Oxfordshire, England \\ (Reçu le 30 décembre 1976, révisé le 16 août 1977, accepté le 5 septembre 1977)
}

\begin{abstract}
Résumé. - Les demandes en puissance et en énergie du Joint European Torus (JET) sont exposées. Les problèmes liés à l'alimentation d'une telle charge par une ligne à haute tension proche des sites proposés sont passés en revue. Une analyse de coût est effectuée et compare les deux alternatives d'alimentation à savoir un ensemble volant-alternateur accouplé à un redresseur ou un transformateur alimentant un redresseur commandé.

La description de l'alimentation en puissance envisagée ainsi que son contrôle et son introduction dans le système global de contrôle terminent cet exposé.

Abstract. - The power and energy requirements of the Joint European Torus (JET) are described. The problems involved in supplying such a load from the H. V. lines adjacent to the proposed JET sites are discussed and a cost comparison is made between the two possible components of the power supply, i. e. flywheel. generator-convertors and transformer-controlled-convertors. The proposed JET power supply system is described, together with an outline of the power supply control and its relationship with the overall JET control system.
\end{abstract}

1. Introduction. - The Joint European Torus (JET) is a large tokamak for which the objective has been stated : to obtain and to study a plasma with conditions and dimensions approaching those needed in a thermo-nuclear reactor [1]. These studies will be aimed at defining the parameters, the size and the working conditions of a tokamak reactor. The machine should operate initially at its basic performance (BP) with a toroidal field $\left(B_{\mathrm{T}}\right)$ of $2.77 \mathrm{~T}$, a plasma with a D-shaped cross-section carrying a current of $3.9 \mathrm{MA}$ and additional heating of $10 \mathrm{MW}$. Subsequently, the operating parameters of the machine will be improved to those for the extended performance (EP) with a $B_{\mathrm{T}}$ of 3.45 T, a D-shaped plasma carrying a current of $4.8 \mathrm{MA}$ and additional heating of at least $25 \mathrm{MW}$. At the BP the machine should operate for about 30 s every $10 \mathrm{~min}$. and have a life of at least 100000 pulses.

The tokamak has large physical dimensions and correspondingly large requirements of power and energy, at least $450 \mathrm{MW}$ and $7000 \mathrm{MJ}$ for the $\mathrm{BP}$ and $700 \mathrm{MW}$ and $7500 \mathrm{MJ}$ for the EP.

For economic reasons, it may be necessary to build the power supply initially for the BP and later to increase its capacity to that necessary for the EP, by the addition of extra units.

The JET power supply system has undergone some modifications since it was last published [2] and every effort has been made to include the latest developments in this paper. It gives a description of the loads, a cost comparison between the two major components of the power supply (flywheel-generator-convertors (FGC) and transformer-controlled-convertors (TCC)) and indicates the influence of the HV lines adjacent to the proposed JET sites on the power supply, by considering the power supply schemes compatible with both a strong and a relatively weak HV line. The power supply control is briefly described, together with its relationship with the overall JET control system.

The power supply system for the EP is described, since it is this which reaches the limits imposed by the HV line and hence determines the design. The differences between the BP scheme and the EP scheme are indicated.

2. Jet loads. - There are four main loads on the JET power supply system [1], which are now considered in turn.

2.1 Toroidal Magnetic Field Coils (Load No. 1). - The toroidal magnet has a self inductance of $660 \mathrm{mH}$ and a resistance of $61 \mathrm{~m} \Omega$ which rises by about $10 \%$ as the temperature of the copper increases during a pulse. Neither the rise nor the decay time is critical for the operation of the JET and, therefore, a rise of about $13 \mathrm{~s}$ (load time constant is $10.8 \mathrm{~s}$ ) and a natural decay have been chosen as a reasonable compromise between peak power and energy per pulse.

For the BP the toroidal field current is $53.4 \mathrm{kA}$, the peak power which is required at the end of the rise time is $240 \mathrm{MW}$ and the average power required during the flat-top is about $180 \mathrm{MW}$. The maximum reactive power requirement is typically $180 \mathrm{MVAR}$ 
and appears as a peak at the end of the flat-top. It is due to the phase control of the rectifiers and its value depends upon the rate at which the real power is reduced to zero. The duration of the flat-top is $20 \mathrm{~s}$ and the energy per pulse is about $5500 \mathrm{MJ}$ of which $940 \mathrm{MJ}$ is stored in the coils.

The current flowing in the coils for the EP is $67 \mathrm{kA}$ and the real and reactive power requirements are as shown in figure $1 a$. The peak power is $360 \mathrm{MW}$, the average flat-top power is $300 \mathrm{MW}$ and the peak reactive power requirement is about 260 MVAR. The flat-top time is only $10 \mathrm{~s}$, owing to the limit imposed by the cooling capability of the coils, and corresponds to approximately the same total energy requirement as for the BP, $5500 \mathrm{MJ}$, of which $1480 \mathrm{MJ}$ is stored in the coils.
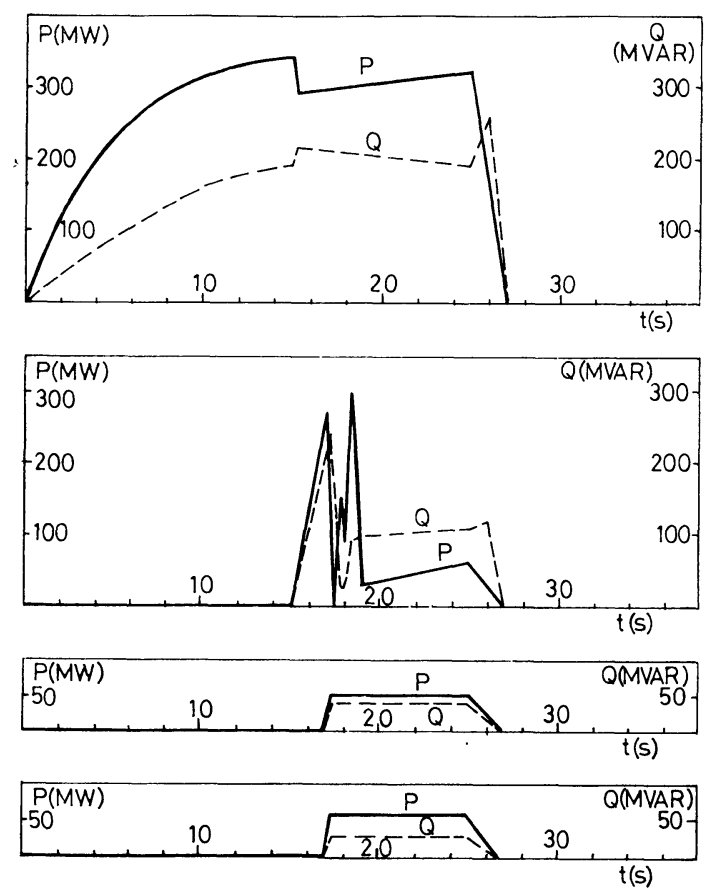

Fig. 1. - Real (P) and Reactive (Q) Power Requirements of the Individual JET Loads for the Extended Performance. a) Toroidal Field Coils (Load No. 1). b) Poloidal Field Coils (Load No. 2). c) Poloidal Field Control Amplifiers (Load No. 3). d) Additional Heating (Load No. 4).

2.2 Poloidal Magnetic Field Coils (Load No. 2). - The poloidal field must both establish the plasma current and control the plasma position and, as a consequence of this, it presents a very rapidly changing load to the power supply [3]. The equivalent inductance and resistance of the load vary in the range 7 to $70 \mathrm{mH}$ and 0.01 to $2.8 \Omega$ respectively.

The real and reactive power required for a typical EP pulse are shown in figure $1 b$, when the peak power required is $300 \mathrm{MW}$, the maximum coil current is $80 \mathrm{kA}$ and the total energy consumed per pulse is $1200 \mathrm{MJ}$. The first peak of power occurs at the end of the premagnetization phase and is followed by the plasma fast rise phase during which the power falls to a low value. The next phase is the plasma slow rise when the power increases to its maximum value before falling again at the beginning of the flat-top, after which it increases slowly to overcome the dissipation in the plasma.

\subsection{The Poloidal Magnetic Field Amplifiers} (LOAD No. 3). - The poloidal field system comprises four sets of coils, at least two of which require a fast current control to keep the plasma ring in the required position during a pulse. This rapid control is provided by four thyristor convertors, which are connected in series with the equilibrium coils and used as amplifiers. The amplifiers should be able to either increase or decrease the current in the coils and the convertors must, therefore, be able to operate as either rectifiers or invertors. It is possible that the power will be changed from its maximum value $\left(P_{\max }\right)$ to its minimum value $\left(P_{\min }\right)$ in $1 \mathrm{~s}$ and vice versa, but it is more probable that it will vary in random steps of about $5 \mathrm{MW}$ in $100 \mathrm{~ms}$.

For both the BP and the EP, $P_{\max }$ will be $50 \mathrm{MW}$, $P_{\min }-30 \mathrm{MW}$, and the average power $20 \mathrm{MW}$. The load required for the poloidal field amplifiers at the EP is shown in figure $1 c$.

2.4 The Additional Heating (Load No. 4). Five different methods of raising the temperature of the plasma above the $1 \mathrm{keV}$, which can be reached by Ohmic heating, are being considered for JET. The power supply should be able to supply each of the heating systems proposed, both independently and when more than one type is used at a time.

Each method requires a high voltage (30-200 kV) power supply with a peak power of up to $25 \mathrm{MW}$ for the BP. For the EP and incrase of the power supply to $60 \mathrm{MW}$ is foreseen (see Fig. $1 d$ ). When neutral injectors are used, repeated faults due to the malfunction of the injectors are expected. The protection system should then interrupt the fault in $10 \mu$ s and reset the supply after $1 \mathrm{~ms}$, a procedure which should be tried ten times before the supply is finally disconnected from the injector.

The supply will comprise modules each comprising two sub modules rated at $33.3 \mathrm{kV}, 25 \mathrm{~A}$ and $0.83 \mathrm{MW}$. The modules may be connected in series or in parallel to match the requirements of whatever heating system is in use.

2.5 The Overall Power Pulse. - The total real and reactive power requirements of JET for both the $\mathrm{BP}$ and the EP are shown in figure 2. It can be seen that for the BP the peak real and reactive power will be $450 \mathrm{MW}$ and $420 \mathrm{MVAR}$, respectively, and for the EP $700 \mathrm{MW}$ and $700 \mathrm{MVAR}$. The estimates of reactive power are based on the assumption that the convertors are part diode bridges and part thyristor bridges, the thyristors being controlled simultaneously. The values ultimately obtained may be less if a more sophisticated convertor design is employed. 

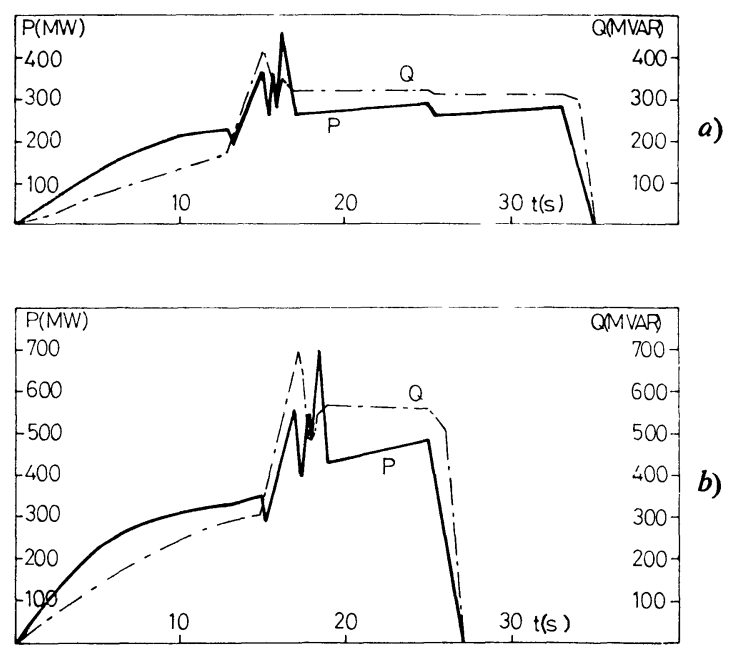

FIG. 2. - Total Real (P) and Reactive (Q) Power Required to Supply the JET Loads. a) Basic Performance (BP). $b$ ) Extended Performance (EP).

In addition to the four main pulsed loads, a continuous AC supply of 15 to $20 \mathrm{MW}$ is required for auxiliaries.

3. H. V. Line. - The direct connection of a pulsating load to a supply line is subject to certain limitations [4] :

(i) The pulse-induced voltage fluctuations must be minimized at the point of common coupling.

(ii) The transmission-angle changes must be small.

(iii) A satisfactory distribution of the pulse energy must be achieved throughout the transmission/generation system.

(iv) The system frequency disturbance must be small.

(v) The load must be substantially harmonic free.

Considerations of voltage fluctuation, transmission angle change and in particular pulse energy distribution demonstrate that maximum benefit is achieved by connecting the pulse load to a system point of high short-circuit intensity.

System frequency disturbance is a function of the magnitude and profile of the pulse energy in relation to the dynamic characteristics of the power system and, hence, can only be reduced by supplying part of the load from another source, e. g. FGC. $[5,6]$.

The amplitude of the pulse-induced voltage fluctuation at the HV interconnection point is dependent on the magnitude and phase of the load current and the impedance of the transmission system. Since the voltage fluctuation is predominantly reactive, it can be minimized by compensation of the inductive components of the load current by a capacitative current. The level of harmonics produced can be controlled by the use of a suitable rectifier and filters may be used to reduce the harmonic load on the network to an acceptable level.
A survey has been made of the characteristics of the HV networks adjacent to the six sites proposed for the construction of JET. At each the characteristics are different and, therefore, impose different constraints on the design and operation of the JET power supply. Following a careful assessment of the various sets of data, it was considered the best policy to select two sets of parameters - representing one strong and one relatively weak network - and to study the implications of each on the final design. This approach has provided two system designs, one of which is suitable for installation at each site without major changes. The two sets of network parameters chosen are shown in table $\mathrm{I}$.

\section{TABLE I}

\section{Typical HV line characteristics}

\begin{tabular}{|c|c|c|c|}
\hline Parameter & Unit & Site A & Site $\mathrm{B}$ \\
\hline Distance between existing HV line & & & \\
\hline and site & $\mathrm{km}$ & $\sim 1$ & $\sim 50$ \\
\hline Line voltage & $\mathrm{kV}$ & 400 & 400 \\
\hline $\begin{array}{l}\text { Short circuit capacity at point of } \\
\text { common coupling }\end{array}$ & GVA & $\gtrsim 15$ & $\lesssim 5$ \\
\hline Power pulse permitted & MW & $\geqslant 450$ & $\leqslant 300$ \\
\hline Voltage drop permitted & $\%$ & $\gtrsim 2$ & $\sim 1$ \\
\hline Reactive power swing permitted & MVAR & $\sim 300$ & $\sim 50$ \\
\hline $\begin{array}{l}\text { Minimum power factor permitted } \\
\text { during a pulse }\end{array}$ & 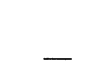 & 0.5 & 0.9 \\
\hline $\begin{array}{l}\text { Maximum permitted rate of change } \\
\text { of power }\end{array}$ & & & \\
\hline Increase & $\mathrm{MW} / \mathrm{s}$ & 200 & $\pi$ \\
\hline Decrease & $\mathrm{MW} / \mathrm{s}$ & 1000 & 50 \\
\hline $\begin{array}{l}\text { Harmonic voltage dist } \\
\text { mitted }\end{array}$ & $\%$ & $\geqslant 2$ & $\leqslant 1$ \\
\hline
\end{tabular}

4. Cost analysis. - Study contracts performed for JET by some of the major manufacturing companies of Europe have provided considerable information about power supply components and their costs $[7,8]$. The costs, which were originally valid for June 1974, have been reassessed both by using further spot checks from the manufacturers and by applying an inflation rate of $15 \%$ per year, which is considered to be the average for Europe in the year 1974-5.

The overall efficiency of a TCC is typically $90 \%$, which is higher than that of a FGC which may fall in the range $50-70 \%$. The actual value of the efficiency depends strongly on the driving system employed and whether or not energy is recovered from the magnet at the end of a pulse. A simple FGC system is considered to be both technically preferable and less expensive for the JET duty and, therefore, a low efficiency system is subsequently considered.

In order to make a comparison between the total costs of TCC and FGC systems over a five year period of JET operation (60 000 pulses at EP), the electricity costs have been evaluated assuming that a TCC has an efficiency of $90 \%$, an FGC has an efficiency of $50 \%$ and the tariffs negotiated by JET at one of its possible sites are applicable. The studies conducted by industry 
for JET have provided the costs for FGC units to supply up to about $2000 \mathrm{MJ}$ and comparisons between FGC and TCC units have been made within this range. A power supply system which is required to supply more than $2000 \mathrm{MJ}$ is then considered to comprise more than one basic unit.

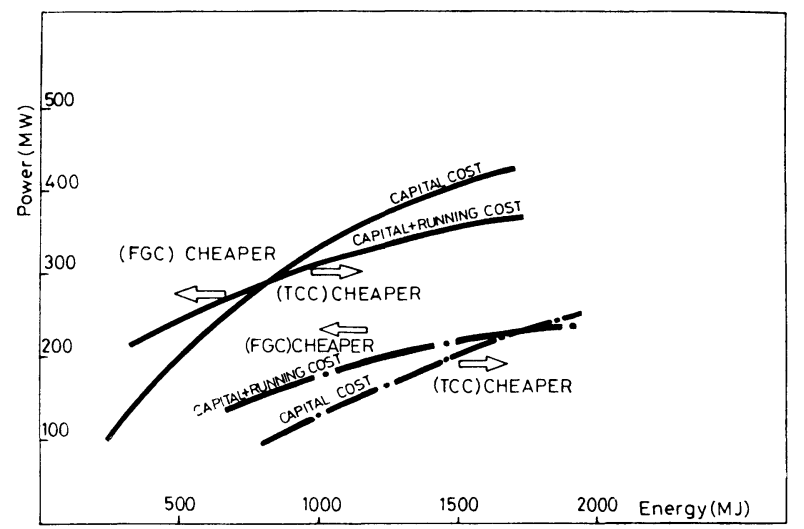

Fig. 3. - Capital and Capital + Electricity Cost Boundaries for Flywheel Generator Convertor (FGC) and Transformer Controlled Convertor (TCC) Power Supply Units. FGC with motor, liquid rheostat and diode convertor. TCC with diodethyristor convertor : - without reactive power compensation for first $300 \mathrm{MW}$; - - - with full reactive power compensation.

Figure 3 shows the cost comparison between complete FGC and TCC units for both capital cost and total cost, i. e. capital cost + electricity costs. It can be seen that where the capital cost is concerned, for a given required load power, the choice between a TCC and an FGC depends strongly on both the energy content of the pulse and the amount of reactive power compensation required, the former being related to the pulse duration and the latter depending on both the strength of the HV line and the design and operation of the TCC. If the electricity costs are considered the TCC appears even more favourable for pulses of high energy content. It is expected that maintenance costs will be less for a TCC.

5. The jet power supply scheme. - Although the JET power supply scheme has not yet been finalised, two power supply schemes suitable to supply the JET at the EP have been proposed, one suitable for installation at each of the sites (A and B) whose $\mathrm{HV}$ line characteristics are listed in table $I$, see figures 4 and 5 respectively. The design is an attempt to match the JET requirements for power, energy and operational flexibility with the characteristics of the HV line, whilst producing an inexpensive scheme. The considerations outlined in sections 3 and 4 indicate that an important proportion of the total JET power can be conveniently taken directly from the HV line at both sites, since the short circuit capacities are high ( $>5$ GVA) and the voltage drops allowed are large $(>1 \%)$. This policy is followed is both of the proposed schemes, where there are two step-down transformers which feed two separate intermediate voltage busbars. The two transformers have the same rating, which provides advantages with respect to spare parts. In the event of a fault in one of the transformers, it is possible to close an isolator between the two busbars and to operate JET as least at the BP using only the remaining transformer.

An attempt has been made to keep at least one of the busbars relatively free from distorsion, so that it is suitable to supply auxiliaries. This is achieved by connecting the two loads which would produce large disturbances, i. e. poloidal field main supply and poloidal field control amplifiers, to one busbar. Even the more stable intermediate busbar may be subject to disturbance and some of the more sensitive auxiliaries may need an independent supply.

In both schemes there is a FGC rated at $200 \mathrm{MW}$ and $600 \mathrm{MJ}$ which is used to supply the poloidal field circuit, alone for the BP and together with a static unit

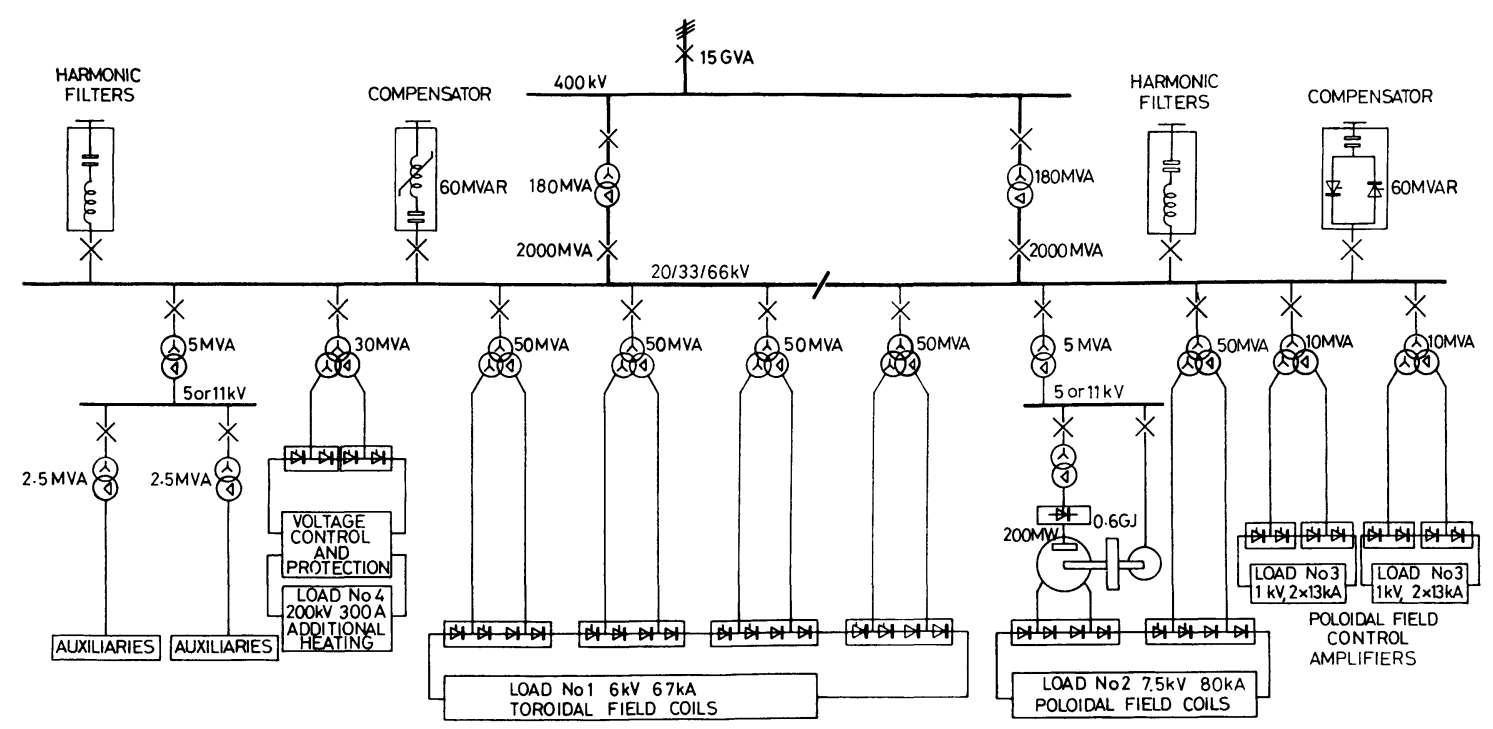

FIG. 4. - JET Power Supply Scheme A 


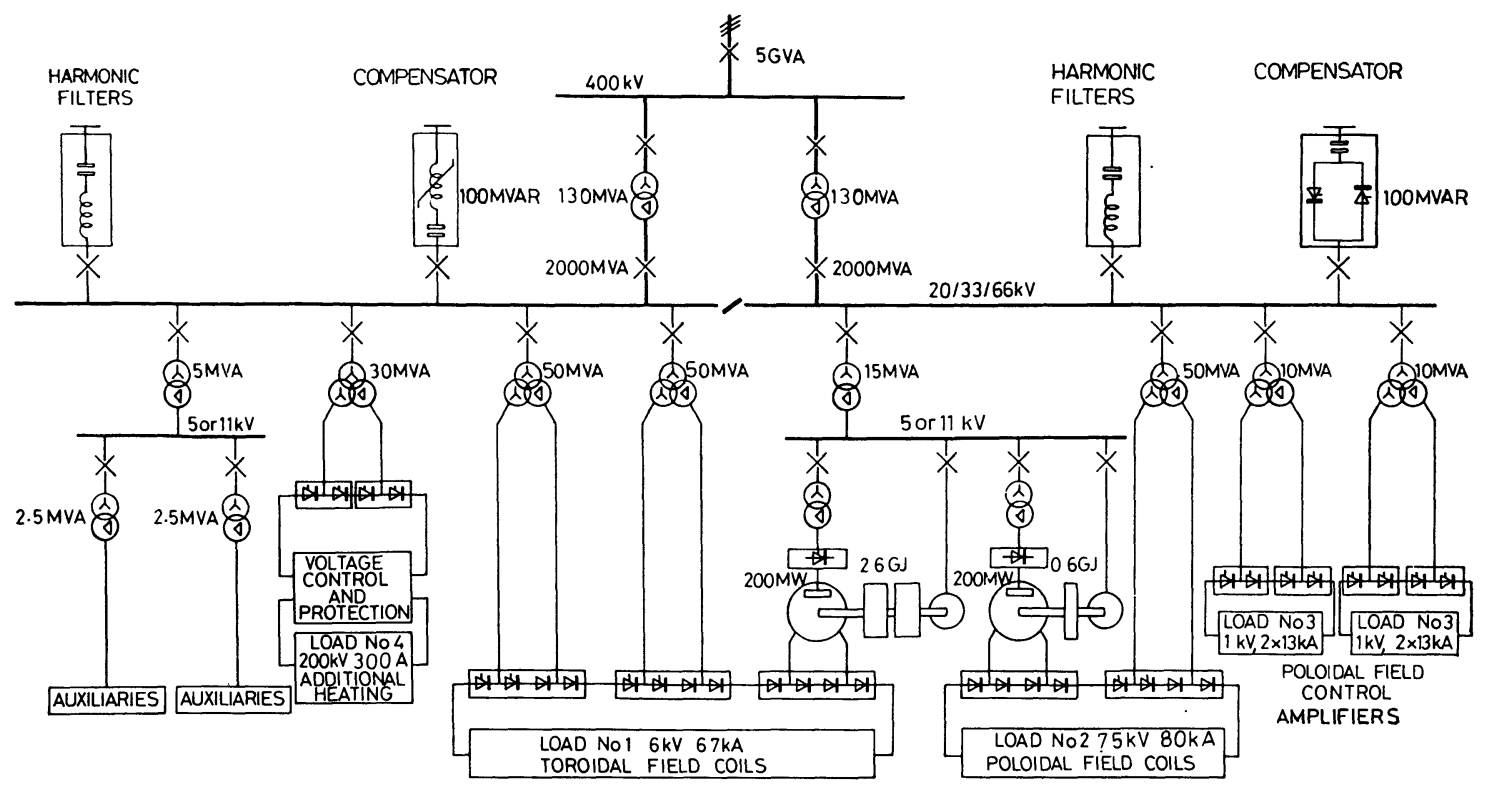

FIG. 5. - JET Power Supply Scheme B.

for the EP. This one generator provides sufficient power derivative shielding of the network, from the rate of change of power required by JET, for the limits imposed (50-200 MW/s over the range of a few hundred MW) not to present a further limit to the design.

The power supply scheme B has a second FGC rated at $200 \mathrm{MW}$ and $2600 \mathrm{MJ}$, which together with two TCC units supplies the toroidal field load. In scheme $\mathrm{A}$ this is replaced by a third and fourth identical TCC unit since the active and reactive power available from the HV line are greater and an even greater proportion of the total power required can be supplied by the network.

Both schemes will require reactive power compensation and filters. The filters are necessary to reduce the voltage waveform distorsion, not only to satisfy the requirements of the Electricity Supply Authorities, but also to avoid problems in the commutation of the rectifying units. The reactive power compensators reduce both the voltage drop at the $\mathrm{HV}$ line point of common coupling to within the limits imposed by the Electricity Supply Authority and that at the intermediate busbar to considerably less than the 10-20\% which might otherwise have occurred, thereby effecting a considerable decrease in the ratings of the TCC units. Although the demand on the HV line is greater for scheme $A$ than for scheme $B$, the optimum rating of compensator may not be larger as the swing permitted is also greater.

It is necessary to install the power supply in stages, one $400 \mathrm{kV} / 20$ or 33 or $66 \mathrm{kV}$ transformer, two toroidal field TCCs and one poloidal field TCC can be purchased later. With the initial installation it would be possible to operate JET for the BP.

6. Control. - Whereas the control for the H. V. substation and auxiliary supply can be considered to be conventional, the control of the JET load power supplies is integrated into the total JET control system. For control purposes, the JET apparatus and the diagnostic devices are divided into a number of subsystems. The subsystems comprise a number of components or local units, each performing a specific function. The supervision of the whole experiment is done at a higher level by a master control centre which co-ordinates the operation of all subsystems.

At the subsystem control level all subsystems require essentially the same functions to be performed and, hence, a unified structure has been adopted for all subsystems, in which a computer is used to provide control, monitoring, interlock and data acquisition functions (see Fig. 6). The co-ordinated operation of the various parts of each subsystem, considered as a whole, is the main duty of the subsystem computer,

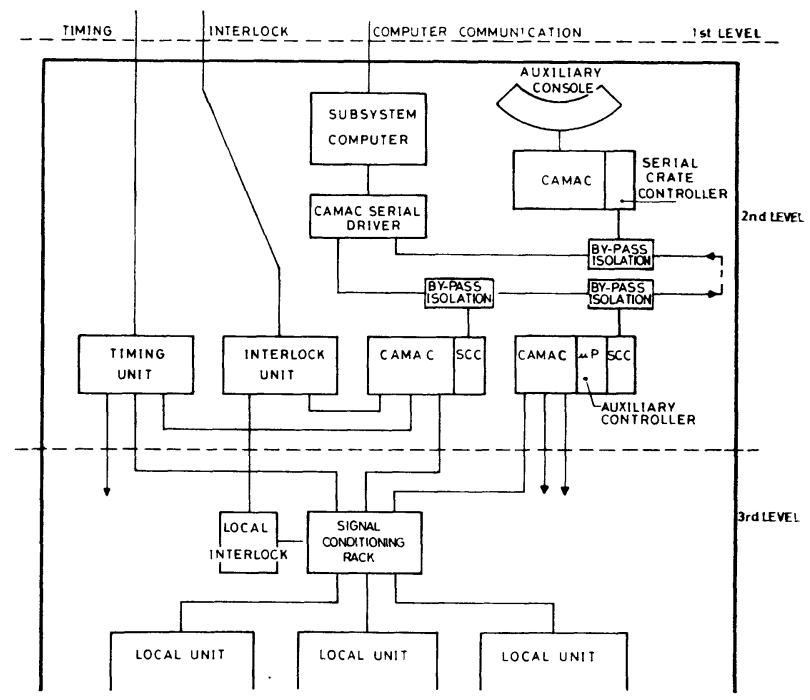

FIG. 6. - General Schematic of a Subsystem of the JET. Control and Data Acquisition System. 
which is linked to the Supervisory level via the communications system. Independent operation of each subsystem is feasible during commissioning and maintenance.

The power supplies are all included within three main subsystems : toroidal field, poloidal field and additional heating. Each of the power supplies is a rather complex subsystem itself, being composed of TCCs and FGCs, which can be regarded as independent units with their own local control and monitoring systems.

The main task of the toroidal field circuit is to provide a toroidal field current corresponding to a preset profile. To achieve this a feedback loop for the toroidal field current is envisaged, which regulates both the static and rotating units to match the reference value.

In the poloidal field system a multi-variable controller acts on the poloidal field power units (main power supplies, amplifiers and switches) in order to control the plasma position, shape and current level.

For the additional heating power units a feedback loop is provided to regulated the HV DC output. The voltage regulation is linked to the overcurrent protection unit.

The controllers are designed to be very versatile since the configuration of the power supplies can change and the additional units necessary for the EP must be accommodated.

Each FGC and TCC can be operated either in the local mode (for commissioning, tests, maintenance, etc.) or in the remote mode (for normal operation in the JET system), when the commands are issued from the overall subsystem control (second level control) under the supervision of the JET master control (first level control).

The protection and interlocking system prevents incorrect operation by inhibiting commands and by reverting equipment into a safe condition.

The monitoring and acquisition system envisaged for each power unit will permit data related to the state of the power supply system to be collected both for on-line monitoring and alarms. Moreover, data can be made available to the JET main data acquisition system for fully recording the pulse.

7. Conclusions. - TCCs are technically superior, more efficient and cheaper than FGCs for supplying loads of several $100 \mathrm{~s} \mathrm{MW}$ and several GJ, as required for JET, if there is a HV line near the site which can supply the energy at a cost based on a low peak power tariff, whilst tolerating high derivatives of power (50-100 MW/s) and necessitating only a limited amount of reactive power compensation $(<150 \mathrm{MVAR})$.

The JET power supply may be installed in stages to supply first tye BP and then the EP ; it may be operated for the BP even if one of the main step-down transformers fails and it makes use of all the pulse power available from the HV network.

Even if JET were built at a site where more than $450 \mathrm{MW}$ is available from the network, the use of the extra power would imply a reactive power swing of more than $500 \mathrm{MVAR}$ and a rate of change of power of up to $1000 \mathrm{MW} / \mathrm{s}$, owing to the control requirements of the poloidal field sys.em. It is improbable that these requirements would also be satisfied and, ther $\in$ fore, the poloidal field generator is considered to be necessary at all possible sites.

References

[1] The JET Project Design Proposal, Published by the Commission of the European Communities as EUR 5516e (march 76).

[2] Bertolini, E., Ciscato, D., Coccorese, E., Hicks, J. B., Selin, K. I., 9th Symposium on Fusion Technology, (Garmisch-Partenkirchen) 1976.

[3] Smart, D. and Dokopoulos, P., 9th Symposium on Fusion Technology, (Garmisch-Partenkirchen) 1976.

[4] BAYARD, O. and Fox, J., International Conference on Sources and Effects of Power System Disturbances, (London) 1974.

[5] HIcks, J. B., 9th Symposium on Fusion Technology, (GarmischPartenkirchen) 1976.

[6] Selin, K. I. and Bertolini, E., 9th Symposium on Fusion Technology, (Garmisch-Partenkirchen) 1976.

[7] Hicks, J. B., JET Power Supply Group Note (76) 12 (jan. 76).

[8] Bertolini, E., JET Power Supply Group Note (75) 4 (nov. 75). 